\title{
F. Pouzin de la Mariniere Benoist, Célianne ou les amants séduits par leurs vertus suivi du Journal en forme de lettres mêlé de critiques et d'anecdotes
}

\section{Elena Aschieri}

\author{
(2) OpenEdition \\ Journals \\ Edizione digitale \\ URL: http://journals.openedition.org/studifrancesi/34788 \\ DOI: $10.4000 /$ studifrancesi.34788 \\ ISSN: 2421-5856

\section{Editore} \\ Rosenberg \& Sellier
}

\section{Edizione cartacea}

Data di pubblicazione: 1 novembre 2005

Paginazione: 426

ISSN: 0039-2944

\section{Notizia bibliografica digitale}

Elena Aschieri, «F. Pouzin de la Mariniere Benoist, Célianne ou les amants séduits par leurs vertus suivi du Journal en forme de lettres mêlé de critiques et d'anecdotes», Studi Francesi [Online], 146 (XLIX | II) | 2005, online dal 30 novembre 2015, consultato il 19 avril 2021. URL: http://journals.openedition.org/ studifrancesi/34788; DOI: https://doi.org/10.4000/studifrancesi.34788

Questo documento è stato generato automaticamente il 19 avril 2021.

\section{cc) $($ ) $\ominus$}

Studi Francesi è distribuita con Licenza Creative Commons Attribuzione - Non commerciale - Non opere derivate 4.0 Internazionale. 


\title{
F. Pouzin de la Mariniere Benoist, Célianne ou les amants séduits par leurs vertus suivi du Journal en forme de lettres mêlé de critiques et d'anecdotes
}

\author{
Elena Aschieri
}

\section{NOTIZIA}

F. POUZIN DE LA MARINIERE BENOIST, Célianne ou les amants séduits par leurs vertus suivi du Journal en forme de lettres mêlé de critiques et d'anecdotes. Présentation et notes d'olga B. Cragg, Sain-Etienne, Publications de l'Université de Saint-Etienne, 2002, pp. 135.

Olga B. Cragg pubblica due opere di Mme Benoist, «blanchisseuse à Lyon / et auteur à Paris», come ironicamente la definì Rétif de La Bretonne. Il primo testo (pp. 37-94) è il romanzo Célianne, pubblicato nel 1766, cinque anni dopo la Nouvelle Héloise. Célianne è moglie di un uomo che lei non ama, che le è stato scelto dalla famiglia. Il marito le presenta il giovane Mozime: in un primo momento tra i due nasce un idillio, rafforzato dalla comune volontà di essere onesti e virtuosi. Quando Mozime sta per cedere alla passione, interviene il marito di Célianne che blocca una situazione ormai insostenibile. Il giovane è allontanato, si sposerà e tornerà dopo un anno per condividere un'amicizia a quattro. I topoi del romanzo sentimentale sono tutti presenti: dai pericoli della seduzione alle illusioni, alla gelosia, ai malintesi, al matrimonio riparatore. La curatrice segnala, nella breve introduzione che precede il romanzo (pp. 7-22), l'evidente legame tra Célianne e la tradizione romanzesca di derivazione rousseauiana, l'ideologia femminista dell'opera e i giochi formali presenti nel testo. Viene infine sottolineata la problematica dei rapporti tra narratrice, eroina e lettore che collegano in qualche modo Mme Benoist a Sterne e Diderot. La seconda parte del volume è occupata dal Journal che Mme Benoist scrive per un'amica (pp. 95-134). Si tratta di sette lettere, che rappresentano la prima opera dell'autrice, pubblicate nel 1757. Questa breve 
corrispondenza a senso univoco, se non vera, totalmente verosimile, è utile per ricostruire la situazione storica ma soprattutto culturale e sociale della donna nel XVIII secolo. Mme Benoist appare moderna, progressista e femminista: segnala lo stato di ignoranza in cui la donna è tenuta, facendo riferimento alle Femmes savantes di Molière, opera da lei esaminata nelle lettere, e difende il diritto, anche per il sesso femminile, alla creazione letteraria; ritiene opportuna, secondo le ultime teorie mediche, l'inoculazione del vaiolo e ci offre, nelle sue narrazioni e descrizioni, uno spaccato della conduite de vie di una donna di Province a metà Settecento.

2 Un'utile Notice Biographique (pp. 23-28) e una Bibliographie (pp. 29-34), completano il volume. 